\title{
SÀNG LỌC TRƯớC SINH KHÔNG XÂM LẤN NIPT VÀ ỨNG DỰG TRÊN 7015 THAI PHỤ TẠI TRUNG TÂM XÉT NGHIỆM QUỐC TẾ GENTIS
}

\section{TÓM TẮT}

Dị tật bẩm sinh là vấn đề toàn câu ảnh hưởng nghiêm trọng tới chất lượng cuộc sống. Trong số những nguyên nhân đã biểt, bất thường di truyền là nguyên nhân phổ biến nhất gây dị tật bẩm sinh. Những năm gần đây kỹ thuất sàng lọc DÑA trước sinh không xâm lấn là một bước tiến lớn trong sàng lọc trước sinh, cho phép sàng lọc ở thời điểm sớm hơn và giảm nguy cơ sảy thai do phải sử dụng các biên pháp xâm lấn. Áp dụng kỹ thuật NIPT, chúng tôi tiển hành đề tài này với muc tiêu: Đánh giá tương quan tỷ lệ lệch bội nhiễm sắc thể với các yếu tố nhóm tuổi thai phụ và kết quả sàng lọc huyết thanh mẹ. Phương pháp: thực hiện kỹ thuật NIPT với bộ kit Truseq Nano DNA LT (Illumina) và giải trình tư trên máy Nextseq 550 (Illumina) cho 7015 thai phụ. Chúng tôi thu được kết quả: phát hiện tỷ lệ thai bị Down là $1,28 \%$, trisomy 18 là 0,24\% và trisomy 13 là 0,2\%. Kết luâan: Tỷ lệ mắc Down là cao nhất, tuổi mẹ cao làm tắng nguy cơ con mắc Down; thực hiện kỹ thuật NIPT làm giảm $98,25 \%$ thai phu phải choc ối.

Tư khóa: sàng looc trước sinh, NIPT, lệch bội nhiễm sắc thể, dị tật bẩm sinh.

\section{SUMMARY \\ NON-INVASIVE PRENATAL TESTING (NIPT) AND ITS APPLICATION IN 7015 CASES AT GENTIS INTERNATIONAL LABORATORY}

Birth defects are a global problem that seriously affects quality of life. Genetic abnormalities are the most common cause of birth defects. In recent years, noninvasive prenatal DNA screening is a major step forward in antenatal screening, allowing for earlier screening and reducing the risk of miscarriage due to the use of invasive methods. Applying NIPT technique, we carried out this topic with the aim: To evaluate the correlation rate of chromosomal aneuploidy with factors of gestational age group and maternal serum screening results. Methods: Performing NIPT technique with Truseq Nano DNA LT kit (Illumina) and sequencing on Nextseq 550 (Illumina) for 7015 pregnant women. We obtained the results: the rate of pregnancy with Down was $1.28 \%$, trisomy 18 was $0.24 \%$ and trisomy 13 was $0.2 \%$. Conclusion: The incidence of Down is the highest, increasing maternal age increases the risk of children getting Down; Implementation of NIPT technique reduces $98.25 \%$ of pregnant women need amniocentesis.

${ }^{1}$ Công ty Cổ phần Phân tích Di truyền (Gentis)

Chịu trách nhiệm chính: Dương Chí Thành

Email: thanhdc@gentis.com.vn

Ngày nhận bài: 9.4.2021

Ngày phản biên khoa hoc: 27.5.2021

Ngày duyệt bài: 10.6.2021

\section{Dương Chí Thành ${ }^{1}$, Nguyễn Văn Huynh ${ }^{1}$, Nguyễn Quang Vinh ${ }^{1}$, Phạm Đình Minh ${ }^{1}$}

Keywords: prenatal screening, NIPT, aneuploidy, birth defects.

\section{I. ĐĂT VẤN ĐỀ}

Ở Việt Nam, 2,01\% các trường hợp tử vong do bệnh có nguyên nhân dị tật, di dạng bẩm sinh và bất thường nhiễm sắc thế [2]. Nhiều nghiên cứu trên thế giới đã cho thấy lệch bội nhiễm sắc thể là nguyên nhân phổ biến nhất gây dị tật bẩm sinh và sảy thai, chiếm $5 \%$ trong tổng số các trường hợp mang thai [6]. Có tới 0,3\% tổng số các ca trẻ sinh sống mang lệch bội nhiểm sắc thể, trong đó chủ yếu là trisomy 21 và lệch bội nhiễm sắc thể giới tính [6]. Hội chứng Down là dạng lệch bội nhiễm sắc thể phổ biến nhất trong các trường hợp sinh sống với tỉ lệ khoảng 1/700 ca đẻ sống [9]. Nguyên nhân phổ biến nhất gây nên $95 \%$ các trường hợp Down là do bất thường số lượng nhiễm sắc thể, cu thể là thừa 1 nhiễm sắc thể thứ 21 (trisomy 21). Các nguyên nhân khác có thể kể đến là Chuyển đoan hòa hợp tâm (Robertsonian translocation) chiếm 2-4\%, nhiễm sắc thể đều/nhiễm sắc thể hình vòng và hội chứng Down thể khảm. Hâu hết người bệnh đối mặt với những ảnh hưởng nghiêm trọng về sức khỏe và khả năng học tập, dị dạng sọ mặt, thính lực, thị lực, giảm trương lực cơ và các dị tật tim ở giai đoạn sơ sinh... Hội chứng Edwards (trisomy 18) và hội chứng Patau (trisomy 13) là 2 dang lêch bội nhiễm sắc thể phổ biến chỉ sau hội chứng Down với tỉ lệ lần lượt là $1 / 3000$ và $1 / 6000[9]$. Ngoài nguyên nhân chính là dư thừa số lượng nhiễm sắc thể, các nguyên nhân liên quan đến bất thường chuyển đoạn nhiễm sắc thể và bất thường thể khảm chiếm hơn $2 \%$ các trường hợp mắc hội chứng Edwards và $9 \%$ các trường hợp mắc hội chứng Patau. Thai nhi mắc hội chứng Edwards hoăc hội chứng Patau thường có nguy cơ cao chết trong bung me hoăc trong 2 tuần đâu sau khi sinh. Những trẻ sống sót sau khi sinh có tỷ lệ mắc các dị tật liên quan rất cao, đặc biệt là các dị tật về tim và hệ thân kinh. Đối với hội chứng Edwards, triệu chứng lâm sàng phổ biển bao gôm dị tật tim (thân chung động mạch, chuyển vị của các động mạch lớn, tấm thất đỡn, thông liên nhĩ thất, tứ chứng Fallot, không lỗ van 3 lá và hẹp, dị thường Ebstein, khuyết tật van phổi, thiểu sản/hẹp van động mạch chủ, tim trái giảm sản, 
tim phải thiểu sản, co thắt đông mạch chủ, bất thường hồi lưu tĩnh mạch phổi toàn phần...), dị tật hệ thần kinh (não úng thủy, tật đầu nhỏ...), chứng teo thực quản, lỗ rò khí quản-thực quản, sứt môi và đối với hội chứng Patau là các dị thường tim, dị thường hệ thống thần kinh trung ương (não úng thủy, dị tật không phân chia não trước/ không có khứu não...), dị tật mắt (không có nhãn cầu/ tật mắt nhỏ...), chứng đa ngón/ thừa ngón, sứt môi, hở hàm. Những dị tật này ảnh hưởng nghiêm trọng đến sức khỏe cũng như khả năng vận động, khả năng phát triển trí tuệ và khả năng học tập của trẻ. Việc phát hiện sớm các bất thường di truyền, đặc biệt là những bất thường có tỷ lệ cao như lệch bội nhiễm sắc thể, có ý nghĩa vô cùng quan trọng trong việc giúp gia đình thai phụ có các biện pháp chẩn đoán trước sinh phù hợp từ đó xác định biện pháp hỗ trợ phù hợp để tối đa hóa chất lượng sinh sản, đảm bảo sức khỏe và chất lượng cuộc sống của đứa trẻ được sinh ra.

Các xét nghiệm trước sinh bao gồm hai loại chính là sàng loc trước sinh và chẩn đoán trước sinh. Các phương pháp chẩn đoán bao gồm xét nghiệm sinh thiết gai nhau hoặc chọc ối được coi là tiểu chuẩn vàng có độ chính xác cao lển tới $97,5 \%-99,6 \%$ [1]. Sàng lọc trước sinh bao gồm các phương pháp: siêu âm, sàng lọc từ huyết thanh mẹ, và sàng lọc DNA trước sinh không xâm lấn (NIPT). Các phương pháp chẩn đoán dựa vào các quy trình gây xâm lấn nên sẽ tiềm ẩn nguy cơ gây sảy thai, cụ thể là khoảng 0,22 $0,44 \%$ đối với chọc ối và $0,1-1 \%$ đối với sinh thiết gai nhau [3]. Việc tìm ra sự lưu hành của DNA thai nhi tư do (cffDNA) trong máu thai phu là một bước tiến quan trọng tạo tiền đề cho những phương pháp sàng lọc DNA trước sinh không xâm lấn. So với các xét nghiệm không xâm lấn khác, xét nghiệm NIPT sử dung DNA lưu hành trong máu mẹ với tỉ lệ phát hiện trisomy 21 , trisomy 18 và trisomy 13 lên tới $99 \%, 98 \%$ và $99 \%[4]$.

Tai Việt Nam, sàng loc trước sinh đã trở trành thường quy và ngày càng được nhiều thai phụ tin dùng. Gần đây, xét ñâniệm NIPT đã được Bộ Y tế đưa vào Hướng Dẫn Chuyên môn kỹ thuật trong sàng loc, chẩn đoán, điều trị trước sinh và sơ sinh ban hành kèm theo quyết định số 1807/QĐ-BYT. Trong nghiên cứu này, chúng tôi khảo sát kết quả sàng lọc DNA không xâm lấn tại Gentis ứng dụng giải pháp công nghê Veriseq NIPT (Illumina, Hoa Kỳ) của 7015 thai phụ xét nghiệm tại Gentis với mục tiêu: Đánh giá tương quan tỷ lệ lệch bội nhiếm sắc thể với các yêu tố nhóm tuổi thai phụ và kêt quả sàng lọc huyêt thanh me.

\section{II. ĐỐI TƯợNG VÀ PHƯƠNG PHÁP NGHIÊN CỨU}

Là đơn vị được chuyển giao công nghệ trực tiếp từ Illumina, Gentis đã ứng dụng xét nghiệm Verifi từ năm 2018. Chúng tôi thực hiện xét nghiệm sàng lọc trước sinh không xâm lấn cho 7015 thai phụ bằng ứng dụng quy trình của hãng illumina, Hoa Kỳ. Mẫu máu của các thai phụ được thu thập và tách chiết cfDNA và chuẩn bị thư viện bằng bộ kit Truseq Nano DNA LT (Illumina). Sau đó DNA được giải trình tự trên máy Nextseq 550 (Illumina). Dữ liệu giải trình tự sẽ được so sánh với với bộ gen người tham chiếu và được sử dụng để tính toán giá trị nhiễm sắc thể chuẩn hóa (Normalized Chromosome Value NCV), từ đó đưa ra kết luận về số lượng của NST cần phân tích.

Dữ liệu thu thập để phân tích kết quả NIPT bao gồm mã ID và ngày sinh của thai phụ, tuổi thai, lý do thực hiện xét nghiệm NIPT, kết quả bất thường phát hiện được. Dữ liệu được xử lý bằng phương pháp thống kê sinh học.

\section{KẾT QUẢ NGHIÊN CỨU}

Xét nghiệm NIPT cho 7015 thai phụ chúng tôi thu được kết quả sau:

\section{Bảng 1. Lý do xét nghiệm}

\begin{tabular}{|c|c|c|}
\hline Lý do xét nghiệm & $\mathrm{n}$ & $\%$ \\
\hline NIPT là xét nghiệm đâu tay & 5185 & 73,91 \\
\hline $\begin{array}{c}\text { Làm xét nghiệm NIPT khi xét } \\
\text { nghiềm sang lọc từ huyết } \\
\text { thanh mẹ có nguy cơ cao }\end{array}$ & 1830 & 26,09 \\
\hline Tổng & $\mathbf{7 0 1 5}$ & \\
\hline
\end{tabular}

Kết quả ở Bảng 1 cho thấy trong số những thai phụ đến làm xét nghiệm sàng lọc không xâm lấn có tới $73,91 \%$ thai phụ chọn NIPT là xét nghiệm đầu tay, không qua xét nghiệm sàng lọc trước sinh từ huyết thanh mẹ.

Bảng 2. Nguy cơ bât thường lệch bội nhiếm sắc thể ở 7015 thai phu

\begin{tabular}{|c|c|c|c|c|}
\hline \multirow{2}{*}{\multicolumn{2}{|c|}{ Nhóm tuổi }} & \multicolumn{3}{|c|}{$\mid$ Trisomy Trisomy|Trisomy } \\
\hline & & 21 & 18 & 13 \\
\hline \multirow{2}{*}{$\begin{array}{c}<20 \\
\mathrm{n}=22(1)\end{array}$} & $\mathrm{n}$ & 0 & 0 & 0 \\
\hline & $\%$ & 0,0 & 0,0 & 0,0 \\
\hline \multirow{2}{*}{$\begin{array}{c}21-25 \\
n=467(2)\end{array}$} & $\mathrm{n}$ & 2 & 2 & 1 \\
\hline & $\%$ & 0,43 & 0,43 & 0,21 \\
\hline \multirow{2}{*}{$\begin{array}{c}26-30 \\
n=1837(3)\end{array}$} & $\mathrm{n}$ & 18 & 3 & 4 \\
\hline & $\%$ & 0,98 & 0,16 & 0,22 \\
\hline \multirow{2}{*}{$\begin{array}{c}31-35 \\
n=1901(4)\end{array}$} & $\mathrm{n}$ & 20 & 3 & 2 \\
\hline & $\%$ & 1,05 & 0,16 & 0,11 \\
\hline \multirow{2}{*}{$\begin{array}{c}36-40 \\
n=1927(5)\end{array}$} & $\mathrm{n}$ & 29 & 4 & 5 \\
\hline & $\%$ & 1,5 & 0,21 & 0,26 \\
\hline
\end{tabular}


VIETNAM MEDICAL JOURNAL N²2 - JUNE - 2021

\begin{tabular}{|c|c|c|c|c|}
\hline $41-45$ & $\mathrm{n}$ & 19 & 3 & 2 \\
\cline { 2 - 5 } $\mathrm{n}=764(6)$ & $\%$ & 2,49 & 0,39 & 0,26 \\
\hline $46-50$ & $\mathrm{n}$ & 2 & 2 & 0 \\
\cline { 2 - 5 } $\mathrm{n}=91(7)$ & $\%$ & 2,2 & 2,2 & 0,0 \\
\hline$>50$ & $\mathrm{n}$ & 0 & 0 & 0 \\
\cline { 2 - 5 } $\mathrm{n}=6(8)$ & $\%$ & 0,0 & 0,0 & 0,0 \\
\hline $\mathrm{P}(1-6)$ & & $<0,05$ & $>0,05$ & $>0,05$ \\
\hline Tổng & $\mathrm{n}$ & 90 & 17 & 14 \\
\cline { 2 - 5 }$=7015$ & $\%$ & 1,28 & 0,24 & 0,2 \\
\hline
\end{tabular}

Kết quả ở Bảng 2 cho thấy: có $80,76 \%$ thai phu nằm trong độ tuổi từ 26-40. Thai phụ nằm trong nhóm tuổi me cao (> 35 tuổi) chiếm 40\%, bao gồm các nhóm tuổi: 36-40 ( $\mathrm{n}=1927)$; 41$45(n=764)$ và $46-50(n=91)$. Thai phụ nằm trong nhóm tuổi mẹ trẻ ( $\leq 35$ tuổi) chiếm $60 \%$, bao gồm các nhóm tuổi <20 ( $\mathrm{n}=22)$; 21-25 (n $=467) ; 26-30(\mathrm{n}=1837)$ và 31-35 $(\mathrm{n}=1901)$ (Bảng 2).

Trong các dạng bất thường phát hiện được, thai hội chứng Down có tỷ lệ cao nhất 1,28\% (90/7015), tiếp đến là thai mang hội chứng Edwards $0,24 \%$ và hội chứng Patau 0,2\%. Không phát hiên trường hợp bất thường nào ở nhóm trước 20 và sau 50 tuổi. Với nhóm thai mang hội chứng Down, tỷ lệ tăng dân từ 21 đến 50 tuổi $(0,43 \%$ - 2,49\%). Với hôi chứng Edwards (trisomy 18), tỷ lệ cũng có xu hướng tăng theo tuổi mẹ, tuy nhiên nhóm tuổi từ 21-25 nằm ngoài xu hướng này với tỷ lệ là 0,43\% cao thứ 2 so với các nhóm tuổi khác. Tỷ lệ hội chứng Patau không tăng theo tuổi mẹ lân lượt là 0,21\% (2125 tuổi), 0,22\% (26-30 tuổi), 0,11\% (31-35 tuổi), 0,26\% (36-40 tuổi) và 0,26\% (36-45 tuổi).

Bảng 3. Nguy cơ bất thường lệch bội nhiễm sắc thể trong nhóm thai phỵ có kết quả sàng lọc huyêt mẹ thai có nguy cớ cao mắc bất thường nhiếm sắc thể

\begin{tabular}{|c|c|c|c|c|}
\hline \multirow{2}{*}{$\begin{array}{c}\text { Nhóm } \\
\text { tuối }\end{array}$} & & $\begin{array}{c}\text { Trisomy } \\
\mathbf{2 1}\end{array}$ & $\begin{array}{c}\text { Trisomy } \\
\mathbf{1 8}\end{array}$ & $\begin{array}{c}\text { Trisomy } \\
\mathbf{1 3}\end{array}$ \\
\hline$<20$ & $\mathrm{n}$ & 0 & 0 & 0 \\
\cline { 2 - 5 } $\mathrm{n}=5(1)$ & $\%$ & 0,0 & 0,0 & 0,0 \\
\hline $21-25$ & $\mathrm{n}$ & 0 & 2 & 0 \\
\cline { 2 - 5 } $\mathrm{n}=99(2)$ & $\%$ & 0,0 & 2,02 & 0,0 \\
\hline $26-30$ & $\mathrm{n}$ & 6 & 1 & 2 \\
\cline { 2 - 5 } $\mathrm{n}=455(3)$ & $\%$ & 1,32 & 0,22 & 0,44 \\
\hline $31-35$ & $\mathrm{n}$ & 9 & 0 & 0 \\
\cline { 2 - 5 } $\mathrm{n}=539(4)$ & $\%$ & 1,67 & 0,0 & 0,0 \\
\hline $36-40$ & $\mathrm{n}$ & 3 & 1 & 2 \\
\cline { 2 - 5 } $\mathrm{n}=527(5)$ & $\%$ & 0,57 & 0,19 & 0,38 \\
\hline $41-45$ & $\mathrm{n}$ & 4 & 1 & 0 \\
\cline { 2 - 5 } $\mathrm{n}=188(6)$ & $\%$ & 2,13 & 0,53 & 0,0 \\
\hline $46-50$ & $\mathrm{n}$ & 0 & 1 & 0 \\
\cline { 2 - 5 } $\mathrm{n}=17(7)$ & $\%$ & 0,0 & 5,88 & 0,0 \\
\hline
\end{tabular}

\begin{tabular}{|c|c|c|c|c|}
\hline$>50$ & $\mathrm{n}$ & 0 & 0 & 0 \\
\cline { 2 - 5 } $\mathrm{n}=0(8)$ & $\%$ & 0,0 & 0,0 & 0,0 \\
\hline $\mathrm{P}(1-7)$ & & $>0,05$ & $>0,05$ & $>0,05$ \\
\hline Tổng & $\mathrm{n}$ & 22 & 6 & 4 \\
\cline { 2 - 5 } $\mathrm{n}=1830$ & $\%$ & 1,2 & 0,33 & 0,22 \\
\hline
\end{tabular}

Kết quả ở Bảng 3 cho thấy: Những thai phụ đã thực hiện sàng lọc từ huyết thanh me và có kết quả nguy cơ cao trước khi sàng lọc NIPT có tổng số 1830 thai phụ, trong đó $83,11 \%$ nằm trong độ tuổi 26-40. Thai phụ > 35 tuổi chiếm $40 \%$, bao gồm các nhóm tuổi: 36-40 ( $n=527)$; $41-45(n=188)$ và $46-50(n=17)$. Thai phụ có tuổi $\leq 35$ tuổi chiếm $60 \%$, bao gồm các nhóm tuổi <20 ( $\mathrm{n}=5) ; 21-25$ ( $\mathrm{n}=99) ; 26-30$ ( $\mathrm{n}=$ 455) và 31-35 ( $n=539)$. Xét tổng số các bất thường, chúng tôi thấy: thai trisomy 21 có tỉ lệ cao nhất 1,2\% (22/1830 trường hợp), tiếp theo là trisomy $180,33 \%(6 / 1830)$ và trisomy 13 0,22\% (4/1830). Đối với trisomy 21 , xét nghiệm NIPT cho kết quả sàng lọc dương tính ở các nhóm tuổi $26-30,31-35,36-40$ và 41-45 với tỉ lê lân lượt là $1,32 \%, 1,67 \%, 0,57 \%$ và $2,13 \%$. Đối với trisomy 18, các nhóm tuổi 21-25, 26-30, 3640, 41-45 và 46-50 có xuất hiện các trường hợp dương tính sau khi sàng lọc NIPT lần lượt là $2,02 \%, 0,22 \%, 0,19 \%, 0,53 \%$ và $5,88 \%$. Đối với trisomy 13, 2 nhóm tuổi $26-30$ và 36-40 có kết quả sàng lọc NIPT dương tính với tỉ lệ lân lượt là $0,44 \%$ và $0,38 \%$. Tổng số các bất thường tam nhiếm phát hiên được qua sàng loc NIPT trên 1830 trường hợp sàng lọc huyết thanh dương tính là 32 trường hợp, trong đó có 22 trường hợp mang trisomy 21, 6 trường hợp mang trisomy 18 và 4 trường hợp mang trisomy 13.

\section{BÀN LUẬN}

Trong nghiên cứu của chúng tôi, có đến $73,91 \%$ các thai phụ chọn làm NIPT là xét nghiêm đâu tay chứng tỏ ngày nay người dân Việt Nam đã chú ý nhiều đến chất lượng thế hệ sau, nên đã chấp nhận làm ngay xét nghiệm sàng lọc có độ chính xác cao này mặc dù giá thành so với xét nghiệm sàng lọc thông thường là khá cao.

Về tỷ lệ các bất thường nhiễm sắc thể: trong nghiên cứu này tỷ lệ thai nguy cơ cao mắc bất thường là khá cao: trisomy 21 lên đến 1,28\%, trisomy 21,18 và 13 tổng là $1,72 \%$ trong khi tỷ lệ mắc Down trong cộng đồng khoảng 1/700, so với nghiên cứu của Trân Đức Phấn [8] tỷ lệ dị tật bẩm sinh chung (các loai trong đó gồm cả bất thường nhiễm sắc thể) cũng chỉ trong khoảng 0,34 - 4,16\%. Tỷ lê phát hiện nguy cơ cao với các bất thường nhiếm sắc thể của chúng tôi cao 
là do đối tượng chúng tôi sàng lọc có một tỷ lệ khá lớn là đã phát hiện nguy cơ cao khi làm sàng bước 1 theo phương pháp thông thường, tiếp nữa là dù xét nghiệm NIPT có tỷ lệ dương tính giá rất thấp nhưng vẫn có, nói cách khác vẫn có một số trường hợp (không nhiều) khi xét nghiệm NIPT cho nguy cơ cao nhưng khi làm xét nghiệm chẩn đoán thì thai vẫn bình thường.

Trong các dạng bất thường phát hiện được trong nghiên cứu của chúng tôi, bất thường trisomy 21 có tỷ lệ cao nhất 1,28\% (90/7015 trường hợp), tiếp đến là trisomy 18: 0,24\% (17/7015 trường hợp) và trisomy 13: 0,2\% (14/7015 trường hợp). Những tỷ lệ này đều cao hơn so với các công bố trên thế giới. Chúng tôi không phát hiện trường hợp dương tính nào ở nhóm trước 20 và sau 50 tuổi. Điều này có thể giải thích là do cõ mẫu của 2 nhóm này ít, phù hợp với sự phân bố bình thường của độ tuổi sinh sản. Theo ACOG, tỷ lệ lưu hành bất thường lệch bội có xu hướng tăng cao khi tuổi me càng lớn đặc biệt là với bất thường trisomy 21 [9]. Trong nghiên cứu của chúng tôi, với trisomy 21 , tỷ lệ tăng dần theo tuổi mẹ từ 21 đến 50 tuối điều này trùng khớp với xu hướng trên thế giới đã công bố [9]. Với trisomy 18 , tỷ lệ cũng có xu hướng tăng theo tuổi mẹ, tuy nhiển nhóm tuổi từ 21-25 nằm ngoài xu hướng này với tỷ lệ là $0,43 \%$ cao thứ 2 so với các nhóm tuổi khác. Đối với trisomy 13, tuy không theo xu hướng tăng dần đều nhưng tỷ lệ lưu hành ở nhóm tuổi cao vẫn cao hơn so với nhóm dưới 35 tuổi. Tỉ lệ trisomy 13 lần lượt là $0,21 \%$ (21-25 tuổi), 0,22\% (26-30 tuổi), 0,11\% (31-35 tuổi), 0,26\% (36-40 tuổi) và $0,26 \%$ (41-45 tuổi). Như vậy, trong tổng số 7015 thai phụ được sàng lọc NIPT, chúng tôi thây rõ ảnh hưởng của tuổi mẹ đối với tỷ lệ thai mắc trisomy 21.

Từ các kêt quả của 1830 trường hợp thực hiện NIPT sau khi có kết quả sàng lọc từ huyết thanh me có nguy cơ cao mắc bất thường nhiểm sắc thể (Bảng 3), có thể thấy các trường hợp thai mang trisomy 21 ở nhóm tuổi $41-45$ có tỷ lệ 2,13\% cao hơn so với nhóm tuổi 26-30 với tỷ lệ $1,32 \%$. Xu hướng tương tự được báo cáo trong nghiên cứu của Neagos và công sự: $3,13 \%$ ở nhóm 41-45 tuổi và 1,88\% ở nhóm 26-30 tuổi [7]. Han và cộng sự đã báo cáo kết quả tương tự với $2,17 \%$ ở nhóm $41-45$ tuổi và $1,23 \%$ ở nhóm 26-30 tuổi [5]. Trong một nghiên cứu gần đây, tỳ lệ lưu hành ở nhóm tuổi $36-40$ của trisomy 21 là $0,38 \%$ và của trisomy 18 là $0,09 \%$, thấp hơn nhiều so với nghiên cứu của chúng tôi. Đối với trisomy 18 và trisomy 13 , tỷ lệ thai mắc ở nhóm tuổi mẹ 26-30 lại cao hơn so với nhóm tuổi 41-45, do đó có thể có các yếu tố khác ngoài tuổi mẹ ảnh hưởng tới việc thai mắc các hội chứng này.

Theo ACOG, xét nghiệm sàng lọc trước sinh sử dụng cfDNA tốt hơn so với các test sàng lọc huyết thanh vì có tỉ lệ phát hiện cao và tỉ lệ dương tính giả thấp[9]. Theo hướng dẫn của Bộ y tế trong quyết định số 1807/QĐ-BYT, trong quá trình sàng lọc trước sinh ở 3 tháng đầu thai kỳ, xét nghiệm NIPT có thể thay thể hoặc bổ sung cho các xét nghiệm huyết thanh PAPP-A và free beta hCG tùy trường hợp. Thai phụ chỉ có kết quả xét nghiệm các chất PAPP-A và free beta hCG nguy cơ cao làm xét nghiệm sàng lọc bằng DNA của thai nhi lưu hành trong máu mẹ (để tăng hiệu quả của sàng lọc) trước khi quyết định thực hiện chẩn đoán trước sinh. Trong nghiên cứu của chúng tôi, trên tổng số 1830 trường hợp thai phụ có kết quả sàng lọc huyết thanh có nguy cơ cao, chỉ có 32 trường hợp dương tính khi thực hiện sàng lọc NIPT. Như vậy, sự bổ trợ của kết quả NIPT sẽ giúp giảm thiểu số thai phụ phải thực hiên các kỹ thuật chẩn đoán trước sinh có xâm lấn là $98,25 \%$.

\section{KẾT LUẬN}

Sau khi khảo sát kết quả sàng lọc DNA trước sinh không xâm lấn cho 7015 thai phụ tại Trung tâm xét nghiệm Gentis, chúng tôi đưa ra một số kết luận sau:

- Thai phụ thực hiện sàng lọc NIPT có độ tuổi $<35$ tuổi là $60 \%$ và $>35$ tuổi là $40 \%$.

- Hội chứng Down có tỷ lệ cao nhất 1,28\%, tỷ lệ phát hiện trisomy 18 là $0,24 \%$ và trisomy 13 là $0,2 \%$. Tuổi me cao liên quan đến sự gia tăng nguy cơ thai mắc hội chứng Down.

- Phương pháp NIPT đã cung cấp thêm thông tin cho các thai phụ cũng như bác sĩ lâm sàng, giảm $98,25 \%$ thai phụ phải thực hiện chẩn đoán trước sinh bằng chọc ối.

\section{TÀI LIÊU THAM KHẢO}

1. Andari V. C. M., Bussamra L. C. S., Tedesco G. D. T., Peixoto A. B. P., Pares D. B. S. P., Braga A., Araujo Júnior E., \& Aoki T. (2020). Noninvasive prenatal testing: Benefits and Gynekologie, 85(1), 41-48.

2. Bộ Y tế. Niên giám thống kê y tế 2018.

3. Dines J. N., Eckel A. M., Cheng E. Y., \& Lockwood C. M. (2018). A Paradigm Shift: Considerations in Prenatal Cell-Free DNA Screening. The Journal of Applied Laboratory Medicine: An AACC Publication, 2(5), 784-796. https://doi.org/10.1373/jalm.2017.023119

4. Gil M. M., Accurti V., Santacruz B., Plana M. 
N., \& Nicolaides K. H. (2017). Analysis of cellfree DNA in maternal blood in screening for aneuploidies: updated meta-analysis. Ultrasound in Obstetrics and Gynecology, 50(3), 302-314. https://doi.org/10.1002/uog.17484

5. Han S. H., Kang J. S., An J. W., Lee A., Yang Y. H., Lee K. P., \& Lee K. R. (2016). Rapid prenatal diagnosis of chromosome aneuploidies in 943 uncultured amniotic fluid samples by fluorescence in situ hybridization (FISH). Journal of Genetic Medicine, 5(1), 47-54. http://www. koreamed.org/SearchBasic.php?RID $=2184447$

6. Hassold T., \& Hunt P. (2001). To err (meiotically) is human: The genesis of human aneuploidy. Nature Reviews Genetics, 2(4), 280291. https://doi.org/10.1038/35066065

7. Neagos D., Cretu R., Sfetea R. C., \& Bohiltea
L. C. (2011). The importance of screening and prenatal diagnosis in the identification of the numerical chromosomal abnormalities. Maedica, 6(3), 179-184. https:// pubmed.ncbi.nlm.nih.gov/ 22368694

8. Trân Đức Phấn, Trương Quang Đạt, Phạn Thanh Phương, Lương Thị Lan Anh, Nguyến Xuân Hùng, Hoàng Thu Lan, Nguyến Thị Lâm (2016). Tình hình dị tật bẩm sinh ở Thanh Khê Đà nănng, Phù Cát - Bình Định và Biên Hòa. Y học thực hành. 1027 (11), 154-i57.

9. Screening for Fetal Chromosomal Abnormalities: ACOG Practice Bulletin Summary, Number 226. (2020). Obstetrics \& Gynecology, 136(4). https:// journals.Iww.com/ greenjournal/Fulltext/ 2020/10000/ Screening_for_ Fetal_Chromosomal_Abnormalities_.40.aspx

\section{ĐÁNH GIÁ KẾT QUẢ CHĂM SÓC SẢN PHỤ VÀ MộT Số YẾU Tố LIÊN QUAN TẠI BỆNH VIỆN QUÂN Y 103}

\section{TÓM TẮT}

Mục tiêu: Đánh giá kết quả chăm sóc sản phụ trong chuyển dạ, ngay sau sinh và một số yếu tố liên quan tại Bệnh viên Quân y 103. Đối tượng, phương pháp nghiên cứu: Nghiên cứu mô tả tiến cứu, thức hiện từ tháng 11 năm 2020 đến tháng 04 năm 2021 trển 288 sản phu trong chuyển da và ngay sau sinh tai Khoa Phụ Sản - Bệnh viện Quân y 103. Dữ liệu thu thâp gôm: Kết quả hoat đông chăm sóc; Môt số yếu tố liên quan đến kết quả chăm sóc... Kết quả: Tỷ lệ chăm sóc tốt đạt $80,9 \%$. Các yếu tố liên quan: Nhóm điều kiên kinh tế ôn định kết quả chăm sóc tốt gấp 6,906 lần nhóm điêu kiện kinh tế thiếu; Có mối liên quan tới kết quả chăm sóc của: số lần đẻ và việc phá thai $(p<0,05)$; Nhóm sản phu tâm lý thoải mái kết quả chăm sóc tốt gấp 4,295 lần nhóm sản phụ tâm lý lo lắng, căng thẳng; Có mối liên quan giữa thời gian chuyến da và kết quả chăm sóc $(p<0,05)$; Nhóm sản phụ dấu hiệu sinh tồn bình thường kết quả chăm sóc tốt gấp 2,402 lần nhóm dấu hiệu sinh tồn không bình thường; Có mối liên quan giữa mức độ đau và kết quả chăm sóc sản phụ $(p<0,05)$; Nhóm sản phụ vỡ ối đúng lúc kết quả chăm sóc tốt gấp 2,57 lần nhóm võ ối non, võ̃ sớm; Có mối liên quan giữa thời gian ră̆n đẻ với kết quả chăm sóc sản phụ $(p<0,05)$; Nhóm sản phu hoc lớp tiền sản kết quả chăm sóc tốt gấp 2,287 lẩn nhóm không học. Kết luận: Tỷ lệ chăm sóc tốt $80,9 \%$. Các yếu tố liên quan kết quả chăm sóc: Điều kiện kinh tế; Số lần đẻ và phá thai; Tâm lý sản

\section{${ }^{1}$ Trường Đại họ Thăng Long}

²Bệnh viện Quân y 103

Chịu trách nhiệm chính: Trần Thị Thu Trang

Email: trangtrang 656@gmail.com

Ngày nhận bài: 7.4.2021

Ngày phản biên khoa học: 24.5.2021

Ngày duyệt bài: 8.6.2021

\section{Trần Thị Thu Trang1, Nguyễn Viết Trung ${ }^{2}$}

phụ; Tham gia học lớp tiền sản; Thời gian chuyển dạ; Dấu hiệu sinh tồn; Mức độ đau; Ối vỡ non, vỡ sớm; Thời gian ră̆n đẻ;

Tứ khóa: sản phụ, chuyển dạ, chăm sóc

\section{SUMMARY}

EVALUATION OF THE RESULTS OF

\section{MATERNAL CARE AND SOME RELATED}

\section{FACTORS AT 103 MILITARY HOSPITAL}

Objectives: To evaluate the results of maternal care in labor, right after birth and some related factors at Military Hospital 103. Subjects, research method: Prospective descriptive study conducted from November 2020 to April 2021 on 288 pregnant women during labor and immediately after birth at the Obstetrics and Gynecology Department - Military Hospital 103. Collected data includes: Results of care activities; some factors related to care outcomes. Results: Good care's percentage accounted for $80.9 \%$. Related factors: The group with good economic conditions got 6.906 times better care results than the group with poor economic conditions. There is a relationship with the outcome of care of number of births and abortions $(p<0.05)$; The group of psychologically comfortable pregnant women had 4.295 times better care results than the group of anxious and stressed maternity; There is a relationship between the time of labor and the outcome of care ( $p$ $<0.05$ ). The group of pregnant women with normal vital signs had 2.402 times bettercare results than the group with abnormal vital signs. There is a relationship between pain level and outcome of maternal care $(p<$ $0.05)$. The group of women whose membranes broke at the right time had 2.57 times better care results than that of the group with premature rupture of membranes. There is a relationship between the time of push and the outcome of maternal care $(p<0.05)$; The group of pregnant women who attended the antenatal 